\title{
Single Dose versus Fractionated Stereotactic Radiotherapy for Meningiomas
}

\author{
Simon S. Lo, Kwan H. Cho, Walter A. Hall, Ronald J. Kossow, Wilson L. Hernandez, \\ Kim K. McCollow, Bruce J. Gerbi, Patrick D. Higgins, Chung K. Lee,
} Kathryn E. Dusenbery

\begin{abstract}
Objective: To evaluate the safety and efficacy of stereotactic radiosurgery (SRS) compared to fractionated stereotactic radiation therapy (FSRT) for meningiomas treated over a seven year period. Methods and materials: Of the 53 patients (15 male and 38 female) with 63 meningiomas, 35 were treated with SRS and the 18 patients with tumors adjacent to critical structures or with large tumors were treated with FSRT. The median doses for the SRS and the FSRT groups were $1400 \mathrm{cGy}$ (500- $4500 \mathrm{cGy})$ and $5400 \mathrm{cGy}$ (4000-6000 cGy) respectively. Median target volumes for SRS and FSRT were $6.8 \mathrm{ml}$ and $8.8 \mathrm{ml}$ respectively. The median follow-up for the SRS and FSRT groups were 38 months (4.1-97 months) and 30.5 months (6.0-63 months) respectively. Results: The five-year tumor control probability (TC) for benign versus atypical meningiomas were $92.7 \%$ vs. $31 \%(\mathrm{P}=.006)$. The three-year TC were $92.7 \%$ vs. $93.3 \%$ for SRS vs. FSRT groups respectively (P=.62). For benign meningiomas, the three-year TC were $92.9 \%$ vs. $92.3 \%$ for the SRS group (29 patients) vs. FSRT group (14 patients) respectively $(\mathrm{P}=.77)$. Two patients in the SRS group and one in the FSRT group developed late complications. Conclusion: Preliminary data suggest that SRS is a safe and effective treatment for patients with benign meningiomas. Fractionated stereotactic radiation therapy with conventional fractionation appeared to be an effective and safe treatment alternative for patients not appropriate for SRS. A longer follow-up is required to determine the long-term efficacy and the toxicity of these treatment modalities.
\end{abstract}

RÉSUMÉ: Dose unique versus radiothérapie stéréotaxique fractionnée dans le traitement des méningiomes. Objectif: Évaluer la sécurité et l'efficacité de la radiochirurgie stéréotaxique (RCS) comparée à la radiothérapie stétéotaxique fractionnée (RTSF) dans le traitement des méningiomes sur une période de sept ans. Méthodes et matériels: Parmi les 53 patients ( 15 hommes et 38 femmes) atteints de 63 méningiomes, 35 ont été traités par RCS et 18, dont la tumeur était adjacente à des structures critiques ou était volumineuse, ont été traités par RTSF. Les doses médianes pour le groupe RCS et le groupe RTSF étaient de 1400 cGy (500 à 4500 cGy) et 5400 cGy (4000 à 6000 cGy) respectivement. Les volumes cibles médians pour les groupes RCS et RTSF étaient de 6,8 ml et 8,8 ml respectivement. Le suivi médian pour les groupes RCS et RTSF étaient de 38 (4,1 à 97) mois et 30,5 (6,0 à 63) mois respectivement. Résultats: La probabilité de contrôle tumoral (CT) à cinq ans, s'il s'agissait de méningiomes bénins plutôt qu'atypiques, était de $92,7 \%$ versus $31 \%(\mathrm{P}=0,006)$. Le CT à trois ans était de 92,7\% versus 93,3\% pour les groupes RCS et RTSF respectivement $(\mathrm{P}=0,62)$. Pour les méningiomes bénins, le CT à trois ans était de 92,9\% pour le groupe RCS (29 patients) versus 92,3\% pour le groupe RTSF (14 patients) (P = 0,77). Deux patients du groupe RCS et un patient du groupe RTSF ont présenté des complications tardives. Conclusion: Les données préliminaires suggèrent que la RCS est un mode de traitement sûr et efficace pour les patients porteurs de méningiomes bénins. La RTSF avec fractionnement conventionnel semble être un traitement alternatif efficace et sûr pour les patients chez qui la RCS n'est pas appropriée. Un suivi plus long est nécessaire pour déterminer l'efficacité à long terme et la toxicité de ces modalités de traitement.

Can. J. Neurol. Sci. 2002; 29: 240-248

Meningiomas constitute approximately $20 \%$ of all primary intracranial tumors. ${ }^{1,2}$ Tumor grade rather than histologic subtype bears clear prognostic importance. ${ }^{3-9}$ Complete surgical excision, if achievable, can produce excellent results without adjunctive therapy. ${ }^{9-11}$ However, meningiomas may recur after surgery and curative resection can result in significant morbidity because of strategic tumor location and old age. ${ }^{12-15}$

Stereotactic radiosurgery (SRS) can deliver a single high dose of radiation to a localized area in the brain for the treatment of meningiomas that are unresectable, recurrent or residual after surgery. However, large tumors and tumors adjacent to vital structures such as optic apparatus and brainstem cannot receive a high single dose of radiation from SRS because of limited

This paper was presented at the Annual Meeting of the Congress of Neurological Surgeons 2002 in San Diego, CA.

From the Departments of Therapeutic Radiology-Radiation Oncology (SSL, KHC,

WAH, RJK, WLH, KKM, BJG, PDH, CKL, KED) and Neurosurgery (WAH),

University of Minnesota Hospital and Clinic, Minneapolis, MN, USA.

Received December 12, 2001. Accepted In Final fORM April 10, 2002.

Reprint requests to: Simon S. Lo, Loyola University Medical Center, Dept. of

Radiation Oncology, Bldg 105, Ste 2944 , 2160 South First Avenue, Maywood, IL 60153 USA. 
tissue tolerance. ${ }^{16-19}$ Fractionated stereotactic radiation therapy (FSRT), which has both physical and radiobiological sparing effects, represents a reasonable alternative to SRS. In this study, we evaluate and compare the safety and efficacy of SRS versus FSRT for the treatment of meningiomas at our institution.

\section{Patients ANd methods}

\section{Patients' characteristics}

Between May 1992 and February 1999, 68 patients were treated with stereotactic radiotherapy (SRS or FSRT) at University of Minnesota using a linac-based radiosurgical system. Indications for stereotactic radiotherapy included unresectable disease, residual disease after subtotal resection, failed previous treatment and patient preference. All patients selected for SRS or FSRT either presented with symptoms or had tumor located near critical structures like the brainstem or the optic apparatus. We were unable to obtain any follow-up information on eight patients who were from out-of-state and they were excluded from the study. Among the 60 evaluable patients, seven were also treated with conventional fractionated radiation therapy with SRS as a boost and were therefore excluded in the analysis. For the remaining 53 patients, 35 and 18 were treated with SRS and FSRT, respectively for newly diagnosed and recurrent meningiomas after surgery and/or radiation therapy. Five patients were treated as an adjunct to subtotal resection of newly diagnosed or recurrent tumor and 48 patients were treated without adjunctive surgery for newly diagnosed or recurrent tumor. Among the 27 patients with recurrent disease, seven had prior radiotherapy to the brain (2400-6000 cGy) for meningioma (five patients), acute lymphocytic leukemia (one patient had craniospinal irradiation as a child) and pituitary adenoma (one patient).

Forty-five patients had one lesion, six had two lesions and two had three lesions. The locations of the 63 meningiomas (47 benign, five atypical and 11 malignant meningiomas) were 10 petroclival, 19 sphenoid and cavernous sinus, one optic nerve sheath, 19 convexity, four cerebellar, four parasagittal and six tentorial. Forty-four meningiomas were treated with SRS and 19 meningiomas with FSRT. Five patients, each with one lesion, also received an intratumoral boost. Patients with meningiomas $<5 \mathrm{~mm}$ from critical structures such as the optic chiasm and brainstem or tumors of large size (usually $4 \mathrm{~cm}$ or larger) were selected for FSRT. The median follow-up for the whole group, SRS group, and FSRT group were 34 months (4.1-97 months), 38 months (4.1- 97 months) and 30.5 months (6.0-63 months), respectively. The median ages for the whole group, SRS group and FSRT group were 66 (22-85), 69 (22-85), and 58.5 (37-80)

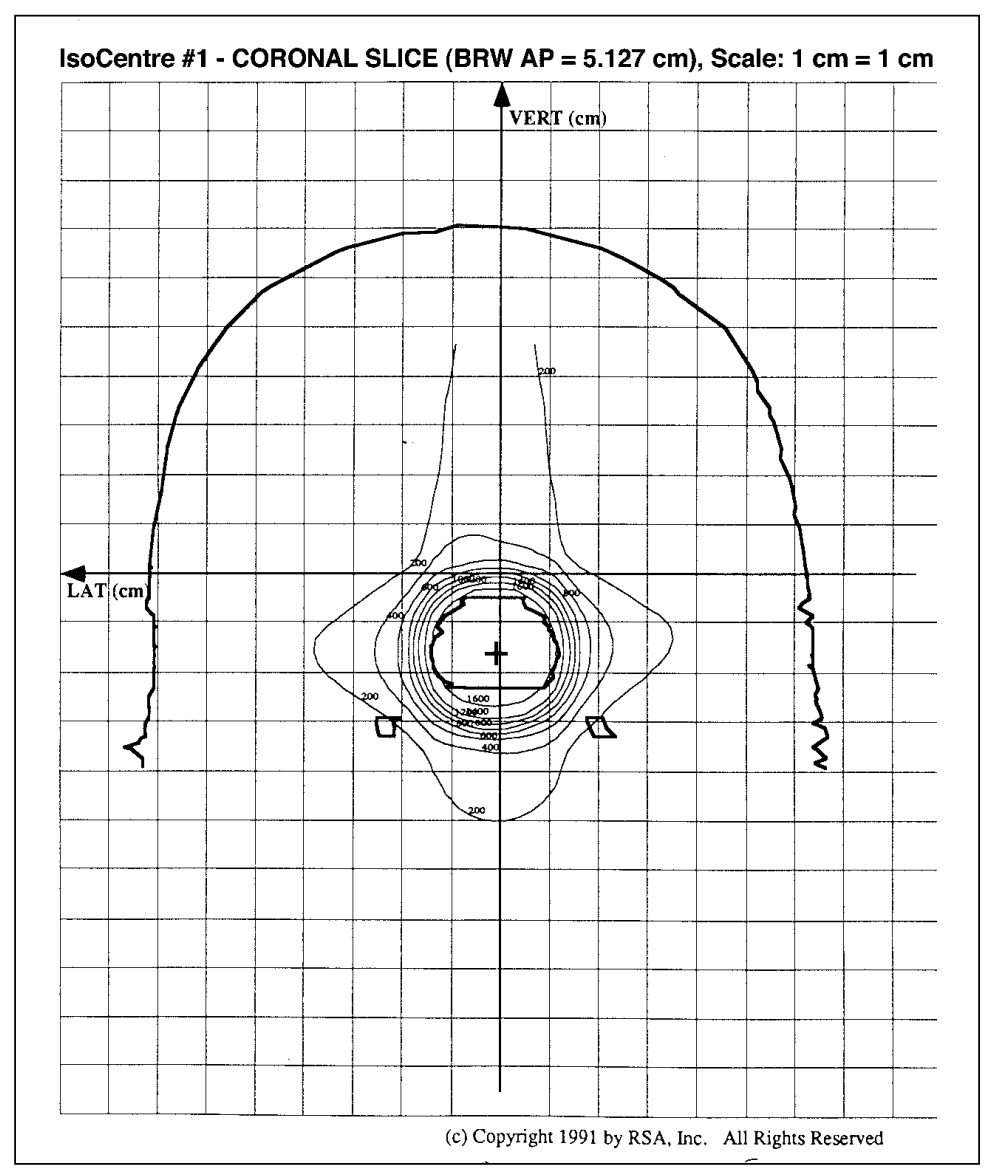

Figure 1: This patient had a midline frontal meningioma and was treated with stereotactic radiosurgery delivering 1500 cGy to the $85 \%$ isodose surface. The tumor showed no evidence of progression 33 months after treatment. 
years, respectively. The corresponding Karnofsky Performance Status were 80 (50-90), 80 (50-90), and 80 (60-90), respectively.

Of the 53 patients in the study, 21 patients (40\%) were diagnosed with meningioma based on typical radiologic criteria without pathologic diagnosis. For the remaining 32 patients (60\%), 25 (48\%) had prior pathologic diagnoses (biopsies were not repeated before SRS or FSRT for recurrence) and seven (12\%) had biopsy-confirmed pathologic diagnosis before SRS or FSRT.

\section{Stereotactic radiotherapy technique and dosimetry}

We first instituted our SRS program on a Philips SL 75-20 linear accelerator operating at $10 \mathrm{MV}$ in 1991. The Philips SRS 200 stereotactic system (Philips Medical System, London, United Kingdom) used standard collimators. The BrownRoberts-Wells stereotactic frame (Radionics, Inc, Burlington, MA) was applied with local anesthesia for head fixation during computerized tomography (CT) and treatment. In 1994, this system was transferred to X-Knife SRS System (Radionics Software Applications, Inc., Burlington, MA) which was compatible with our Varian 6/100 linear accelerator. The relocatable Gill-Thomas-Cosman headframe (Radionics Inc., Burlington, MA) for FSRT was introduced to our program in 1995. The treatment planning process for SRS and FSRT was identical except for the headframe. The target volume (TV) of the tumor was defined as the contrast-enhancing tumor on the CT. The target and the dose-limiting structures such as the eyes, optic nerve, optic chiasm, brainstem were delineated on CT. The number of isocenters, sizes of the collimators $(5-75 \mathrm{~mm})$, and

Table 1. Summary of MRI/CT findings for the 53 patients with 63 tumors

\begin{tabular}{|c|c|c|c|c|c|}
\hline \multicolumn{2}{|l|}{ Radiographic } & \multicolumn{4}{|c|}{ Number of tumors } \\
\hline Response & $\begin{array}{l}<6 \\
\operatorname{mos}\end{array}$ & $\begin{array}{l}6-12 \\
\operatorname{mos}\end{array}$ & $\begin{array}{l}12-24 \\
\text { mos }\end{array}$ & $\begin{array}{l}24-36 \\
\text { mos }\end{array}$ & $\begin{array}{l}>36 \\
\operatorname{mos}\end{array}$ \\
\hline \multicolumn{6}{|l|}{ All } \\
\hline Shrinkage & $2(1)^{*}$ & $5(1)^{*}$ & 1 & $5(1)^{*}$ & 5 \\
\hline No change & $4(2)^{*}$ & $3(1)^{*}$ & $10(3)^{*}$ & 9 & $11(2) *$ \\
\hline Local progression & $1(1)^{*}$ & 0 & 1 & 1 & $5(4)^{*}$ \\
\hline \multicolumn{6}{|l|}{ SRS } \\
\hline Shrinkage & 1 & $5(1)^{*}$ & 1 & 2 & 4 \\
\hline No change & $3(2)^{*}$ & 2 & $8(2)^{*}$ & 3 & $8(2)^{*}$ \\
\hline Local progression & $1(1)^{*}$ & 0 & 0 & 1 & $5(4)^{*}$ \\
\hline \multicolumn{6}{|l|}{ FSRT } \\
\hline Shrinkage & $1(1)^{*}$ & 0 & 0 & $3(1)^{*}$ & 1 \\
\hline No change & 1 & $1(1)^{*}$ & $2(1)^{*}$ & 6 & 3 \\
\hline Local progression & 0 & 0 & 1 & 0 & 0 \\
\hline
\end{tabular}

MRI, magnetic resonance imaging; CT, computer tomography, SRS, stereotactic radiosurgery; FSRT, fractionated stereotactic radiotherapy.

*Parentheses indicate the number of atypical or malignant meningiomas (The numbers not in parentheses include all meningiomas - benign, atypical and malignant). number of arcs and degrees of gantry rotation were selected to optimize the delivery of radiation dose to the target while minimizing the dose to the adjacent normal brain parenchyma. The minimal peripheral dose (MPD) encompassing the target was chosen for dose prescription and the prescribed dose was normalized to the maximum dose within the TV (Figure 1). For the intratumoral boost, the isodose surface to which MPD was prescribed was located within the TV, so the dose delivered to the surrounding brain tissue was minimized due to the rapid fall-off. The number of isocenters used ranged from one to four with a median of one in the SRS group while that used in the FSRT group ranged from one to two with a median of one. The median TVs for the SRS and the FSRT groups were $6.8 \mathrm{ml}(0.5-34 \mathrm{ml})$ and $8.8 \mathrm{ml}(2.4-58.6 \mathrm{ml})$, respectively. The median sizes of the collimators used were $28 \mathrm{~mm}(12-60 \mathrm{~mm})$ and $40 \mathrm{~mm}(18-75$ $\mathrm{mm})$ for the SRS and FSRT groups respectively. The median MPD for the SRS group was 1400 cGy (500- 4500 cGy) at $75 \%$ IDS (50-100\% IDS) and the median MPD for FSRT was 5400 cGy (4000-6000 cGy) at $88 \%$ IDS (60-90\% IDS) in a median of 30 fractions (16-31 fractions). The fraction sizes for FSRT ranged from 180- $250 \mathrm{cGy}$ with a median of $180 \mathrm{cGy}$. An intratumoral boost (a single SRS dose of $600 \mathrm{cGy}$ ) was given in addition to FSRT to five patients with large tumors adjacent to critical structures such as the optic chiasm. All the seven reirradiated patients had an overlap between the previous radiation field and the TV.

\section{Follow-up and endpoints}

Follow-up of patients consisted of clinical examination and CT or magnetic resonance imaging (MRI), which were done at our institution or outside institutions. Patients who lived out of town or state were followed by their physicians locally and patients' information was forwarded to us for review. If necessary, patients were contacted by phone for the monitoring of their clinical status. All of the 53 patients in the study had radiologic follow-up after treatment.

The endpoints used were tumor control probability (TC), local control rate (LC) and cause-specific survival (CSS). Tumor control was defined as the lack of evidence of in-field or marginal failure in each individual tumor on follow-up CT or MRI. A stable appearance or shrinkage of the tumor seen on the CT or MRI was regarded as tumor control. Local control referred to no evidence of local failure in each individual patient. Regional failure, which was defined as recurrence completely outside of the treatment volume, was not counted as local recurrence. Cause-specific survival was defined as no death as a result of meningioma or treatment complication. The acute and late toxicity of the treatment was also evaluated.

\section{Statistical analysis}

Kaplan-Meiers survival analysis was used to compare the TC, LC and CSS between the SRS and the FSRT groups. Identification of prognostic factors predicting TC was attempted using Cox regression.

\section{Results}

\section{Treatment outcome}

The three-year and five-year CSS for the whole group was 93.9\% and $89.4 \%$. The three-year CSS for the SRS vs. the FSRT 
Table 2. Recurrences after Stereotactic Radiosurgery and Fractionated Stereotactic Radiotherapy

\begin{tabular}{|c|c|c|c|c|c|c|c|}
\hline $\begin{array}{l}\text { Patient } \\
\text { No. }\end{array}$ & Location & $\begin{array}{l}\text { Tumor } \\
\text { Grade }\end{array}$ & $\begin{array}{l}\text { Prior treatment } \\
\text { before SRS/FSRT }\end{array}$ & $\begin{array}{l}\text { SRS/FSRT } \\
\text { Dose }\end{array}$ & $\begin{array}{l}\text { Target } \\
\text { volume(cc) }\end{array}$ & $\begin{array}{l}\text { Time to } \\
\text { recurrence }\end{array}$ & $\begin{array}{l}\text { Type of } \\
\text { recurrence }\end{array}$ \\
\hline 1 & Parasagittal & B & Surgery X 1 & $2000 \mathrm{cGy} / 50 \%$ & 14.1 & 71 months & Marginal \\
\hline 3 & $\begin{array}{l}\text { Parietal X 2, } \\
\text { Frontal X } 1\end{array}$ & M & Surgery $X 2 * *$ & $\begin{array}{l}1200 \mathrm{cGy} / 50 \% \\
\text { for } 2 \text { parietal } \\
\text { lesions in one } \\
\text { volume and } \\
2000 \mathrm{cGy} / 85 \% \\
\text { for frontal lesion }\end{array}$ & $\begin{array}{l}.5,8.6 \\
8.8\end{array}$ & 44 months & Local \\
\hline 4 & Frontal & M & Surgery X 2 & $4500 \mathrm{cGy} / 70 \%$ & 4.2 & 3 months & Local \\
\hline 6 & $\begin{array}{l}\text { Cavernous } \\
\text { sinus }\end{array}$ & B & No prior surgery & $\begin{array}{l}4000 \mathrm{cGy} / 90 \% \\
\text { in } 16 \text { fractions }\end{array}$ & 7.2 & 18 months & Local \\
\hline 7 & $\begin{array}{l}\text { Occipital X 1, } \\
\text { Frontal X 1, } \\
\text { Parietal X } 1\end{array}$ & A & Surgery X 2 & $\begin{array}{l}1200 \mathrm{cGy} / 80 \% \\
\text { for all } 3 \text { lesions }\end{array}$ & $\begin{array}{l}1.3,4.2, \\
8.9\end{array}$ & 21 months & Regional \\
\hline 8 & $\begin{array}{l}\text { Cerebellum } \\
\text { X } 2\end{array}$ & M & $\begin{array}{l}\text { No surgery or } \\
\text { XRT to brain } * * *\end{array}$ & $\begin{array}{l}3000 \mathrm{cGy} / 50 \% \\
\text { for both lesions }\end{array}$ & $2.6,4.2$ & 66 months & Regional \\
\hline
\end{tabular}

SRS, Stereotactic radiosurgery; FSRT, fractionated stereotactic radiotherapy; XRT, external beam radiation therapy; B, benign meningioma; A, atypical meningioma; M, malignant meningioma.

* Patient underwent craniospinal irradiation for acute lymphocytic leukemia 20 years prior to SRS.

** Patient had subtotal resection of meningiomas 3 months before SRS.

*** Patient had 4 surgeries and 3 courses of XRT to the spine for metastatic meningiomas.

Table 3. Summary of the doses for the seven patients who had prior radiation therapy

\begin{tabular}{|c|c|c|c|c|}
\hline & $\begin{array}{l}\text { Prior radiotherapy } \\
\text { doses }\end{array}$ & $\begin{array}{l}\text { SRS/FSRT } \\
\text { doses }\end{array}$ & $\begin{array}{l}\text { Treatment } \\
\text { volume }(\mathrm{ml})\end{array}$ & Histology \\
\hline \multirow[t]{2}{*}{ Patient 1} & $5400 \mathrm{cGy}$ & $1600 \mathrm{cGy} / 88 \%$ & 6.5 & Benign \\
\hline & & $1600 \mathrm{cGy} / 90 \%$ & 13 & \\
\hline \multirow[t]{2}{*}{ Patient 3} & $5000 \mathrm{cGy}$ & $2000 \mathrm{cGy} / 70 \%$ & 19.7 & Malignant \\
\hline & & $2000 \mathrm{cGy} / 70 \%$ & for 2 lesions & \\
\hline Patient 4 & 2400 cGy* & $1200 \mathrm{cGy} / 50 \%$ & 68.6 & Atypical \\
\hline Patient 6 & $6000 \mathrm{cGy}$ & $4500 \mathrm{cGy} / 85 \%$ (18 fractions) & 92 & Malignant \\
\hline Patient 7 & $5400 \mathrm{cGy}$ & $5000 \mathrm{cGy} / 90 \%$ (20 fractions) & 6.5 & Malignant \\
\hline
\end{tabular}

*Craniospinal irradiation for leukemia. 


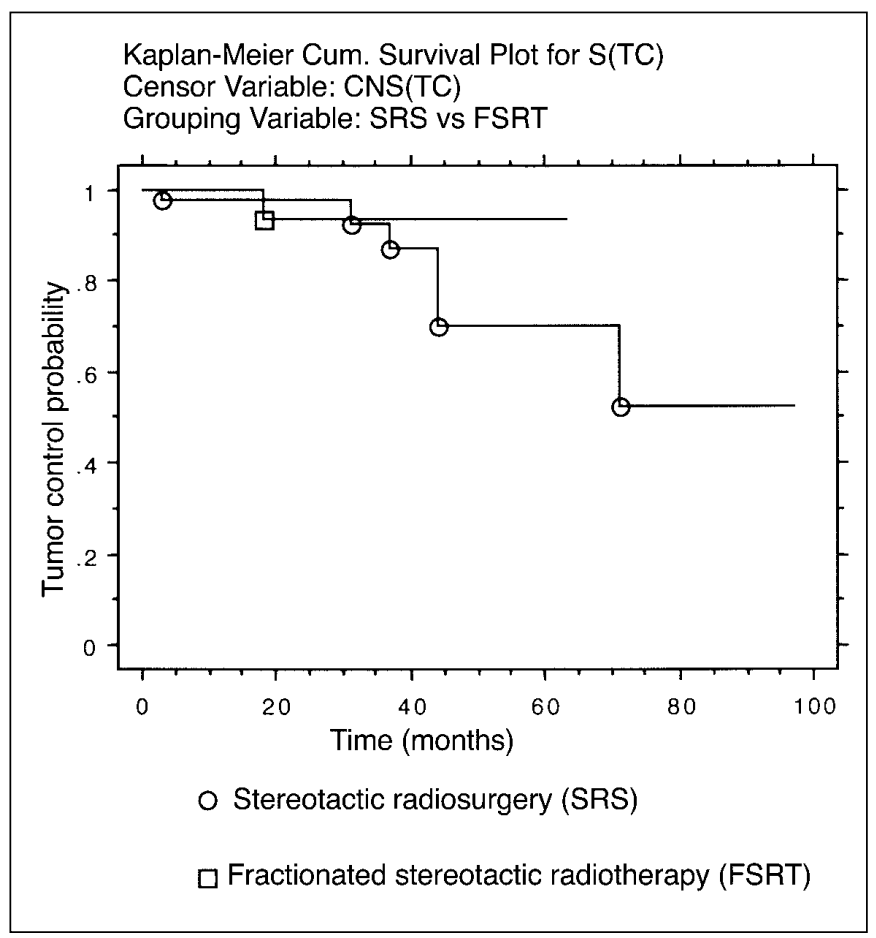

Figure 2: The comparison of tumor control probability for SRS and FSRT of all meningiomas $(P=0.62)$.

groups were $94.1 \%$ vs. $93.3 \%$, respectively $(\mathrm{P}=0.79)$. The fiveyear TC were $90.7 \%$ and $31 \%(\mathrm{P}=0.006)$ for benign and atypical/malignant meningiomas, respectively. The three-year TC were $92.7 \%$ vs. $93.3 \%$ for SRS vs. FSRT groups respectively $(\mathrm{P}=0.62)$ (Figure 2). Seven tumors treated with SRS and one treated with FSRT progressed (15.9\% vs. 5.2\%, $\mathrm{P}=0.25)$. The three-year LC were $91 \%$ vs. $92.9 \%$ for SRS vs. FSRT groups respectively $(\mathrm{P}=0.62)$. Five patients in the SRS groups and one in the FSRT group had evidence of local recurrence radiologically $(14.3 \%$ vs. $5.6 \%, \mathrm{P}=0.35)$. For benign meningiomas, the three-year TC were $92.9 \%$ and $92.3 \%$, respectively ( $\mathrm{P}=0.77$ ) (Figure 3); two tumors treated with SRS and one tumor treated with FSRT progressed $(6.3 \%$ vs. $6.7 \%$, $\mathrm{P}=0.96$ ). For the 43 patients with 47 benign meningiomas, the three year LC were $92.3 \%$ vs $91.7 \%$ for SRS (29 patients) vs. FSRT (14 patients) groups ( $\mathrm{P}=0.8)$; two patients in the SRS and one in the FSRT group had evidence of local recurrence $(6.9 \%$ vs. $7.1 \%, \mathrm{P}=0.98$ ).

Table 1 shows a summary of the radiologic response after SRS and FSRT. When all the tumors were considered, the tumor shrinkage rates were $29.5 \%$ (13/44) and 26.3\% (5/19) for the SRS and the FSRT groups, respectively $(\mathrm{P}=0.80)$. When only the benign meningiomas were considered, the corresponding tumor shrinkage rates were $37.5 \%(12 / 32)$ and 20\% (3/15), respectively $(\mathrm{P}=0.24)$.

\section{Patterns of failure}

Eight patients developed recurrence. Five had atypical or malignant meningiomas and three had benign tumors. Seven patients in the SRS group developed recurrence whereas only

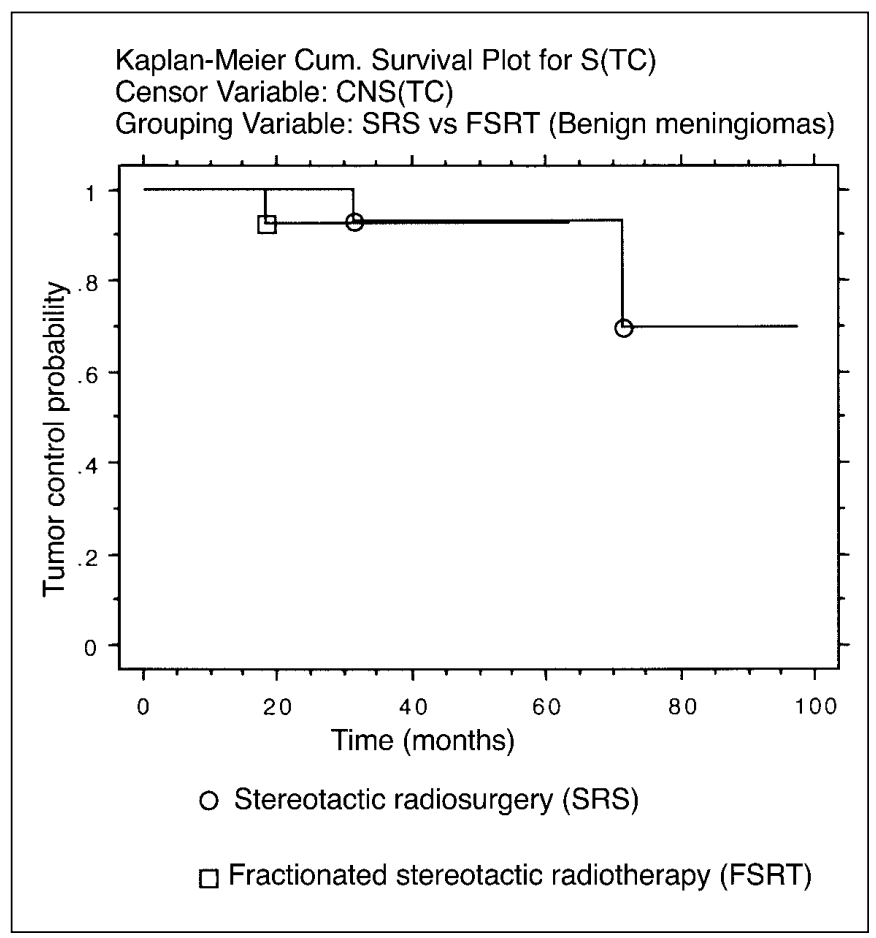

Figure 3: The comparison of tumor control probability for SRS and FSRT for benign meningiomas $(P=0.77)$.

one in the FSRT group progressed. Six patients had local recurrence (five had recurrence within the treatment volume and one at the margin) and two had regional recurrence (outside of treatment volume). Both regional recurrences occurred in patients with atypical (one patient) or malignant meningiomas (one patient). One patient with meningiomatosis developed progression in one of the benign meningiomas not previously treated with SRS. Table 2 summarizes these events.

\section{Prognostic factors}

On univariate and multivariate analyses of the five factors which included tumor location (skull base vs. nonskull base), disease status (primary vs. recurrent), histology (benign vs. atypical/malignant), tumor size $(\leq 3 \mathrm{~cm}$ vs. $>3 \mathrm{~cm})$ and type of treatment (SRS vs. FSRT), only histology predicted TC.

\section{Complications}

The treatments were well-tolerated in general. None of the patients developed symptoms that required active intervention during or immediately after treatment. None of the seven reirradiated patients developed late complications. Table 3 summarizes the doses administered.

All patients had their pretherapy and post-therapy neurocognitive function recorded in the charts. None of them developed any deterioration after SRS or FSRT. However, two patients in the SRS group developed late complications. The first patient was a 69-year-old lady with a recurrent benign left optic nerve sheath meningioma treated with surgery in 1992. She presented with decreased visual acuity in the left eye at recurrence. She had subtotal resection of her recurrent tumor 
before SRS. Stereotactic radiosurgery was offered to her to prevent tumor progression which might potentially cause further damage to left optic nerve. The treatment volume was $14.1 \mathrm{ml}$ and the dose was 800 cGy delivered to the $100 \%$ isodose line. She developed progressive deterioration of vision in the left eye 36 months after SRS. MRI showed no evidence of tumor progression 97 months after SRS.

The other patient was a 74-year-old lady with a newly diagnosed benign right cavernous sinus meningioma presenting with persistent headache treated with SRS in 1996. No surgery was performed before SRS. SRS was offered to her for symptomatic control. 1200 cGy was delivered to a volume of 45 $\mathrm{ml}(90 \%$ IDS) with an intratumoral boost of $300 \mathrm{cGy}$ delivered to a volume of $7.5 \mathrm{ml}$ (90\% IDS). Her symptom improved after the treatment but she developed symptomatic brain necrosis associated with brain edema six months after SRS. Follow-up MRI showed no evidence of tumor recurrence. Her brain edema was well-controlled with steroids and surgery was not required.

One patient in the FSRT group developed a late complication. She was a 80-year-old lady with a newly diagnosed benign sphenoid wing meningioma treated in 1997. No surgery was done before FSRT. Fractionated stereotactic radiation therapy was offered because the tumor was very close to the optic chaism. $5400 \mathrm{cGy}$ in 30 fractions were delivered to a volume of $40 \mathrm{ml}$ (90\% IDS). She noticed progressive deterioration in visual acuity after 14 months. There was no evidence of progression on follow-up MRI.

\section{Discussion}

\section{Surgical resection}

The LC rate after complete resection of meningioma was reported to be in the range of $88-100 \%$ for benign meningiomas. ${ }^{8,9,11,13,20}$ However, patients with exceptional surgical risk factors such as advanced age, poor functional status, and strategic tumor locations are considered poor candidates for surgery which aims for complete tumor resection. ${ }^{12,14,15}$ Subtotal resection, which carries significant morbidity and mortality for poor risk patients, offers much worse LC, which was on the order of $40 \%$ at five years. ${ }^{3,8,9}$ Mirimanoff et $\mathrm{al}^{11}$ reported a 10 -year progressionfree survival of $80 \%$ for patients who had a complete resection for benign meningioma compared to only $45 \%$ for those who had subtotal resection in a series of 225 patients. Another series demonstrated that patients whose tumors were not completely removed had a 4.2-fold relative excess risk of death when compared to patients whose tumors were completely removed. ${ }^{10}$

With the sophistication of neuroradiologic and microsurgical techniques over the past decade, meningiomas that were previously considered unresectable or were located near the brainstem or in the skull-base could now be treated surgically with fair to good outcomes. ${ }^{21-25}$ Despite these advances, there were still significantly high rates of perioperative and long-term neurological morbidity reported in those microsurgical series.

\section{Conventional external beam radiotherapy}

Another treatment modality that has been employed for meningioma is conventional external beam radiation therapy, either as a primary treatment, as an adjunct to surgery or for unresectable or recurrent tumors. ${ }^{3-9,26-29}$ Multiple series showed that postoperative radiation therapy could substantially improve the local control and overall survival for subtotally resected meningiomas. Eight to ten-year local control rates of about $80 \%$ or above were achieved in multiple series with radiation therapy. 5,6,9,26,27,29 For patients with unresectable tumors treated with external beam radiotherapy, the local control rate at 10 years is $46 \% .{ }^{5}$ Complication rates reported ranged from zero to $17 \% .^{3,9,26,28}$

\section{Stereotactic radiotherapy}

Results of SRS have been reported in multiple series and the two- to eight-year tumor control rates were in the range of 75$100 \%$ for benign meningiomas with a median follow-up ranging from 14 to 48.4 months. ${ }^{30-43}$ There does not seem to be any significant difference in local control rates between the Gamma Knife and LINAC-based SRS series.

For tumors that are large in size or close to critical structures such as the optic apparatus and the brainstem, the delivery of a single dose of radiation that is necessary to control the meningioma might not be feasible due to the concern of late complications of those sensitive structures with low tolerance to a single high dose of radiation such as the optic apparatus or brainstem. ${ }^{16-19}$ FSRT combines the advantages of accurate focal dose delivery of radiation dose with a stereotactic technique and the normal tissue sparing effect of fractionated radiation therapy. Recently, 5- and 10-year actuarial overall survival rates of $97 \%$ and $96 \%$ at a mean follow-up of 35 months for 189 patients with World Health Organization (WHO) grade I and II meningiomas treated with FSRT were reported by the Heidelberg group. ${ }^{44}$ Local failure was observed in three of 180 patients with WHO grade I tumors and two of nine patients with WHO grade II tumors. Clinically significant treatment-related toxicity was observed in $1.6 \%$ of the patients.

In our series, the three-year LC for the 35 patients with benign meningiomas treated with LINAC-based SRS was comparable to that reported in the literature and the late complication rate was low (2/35). However, there were some patients in our series who were not amenable to SRS alone because of the large tumor size or the proximity of the tumor to critical structures. Before the availability of the relocatable headframe, those patients were treated with conventional fractionated radiation therapy followed by SRS boost, aiming at adding a lower focused single high dose of radiation to improve tumor control.

Radiobiologically, conventional fractionated radiation therapy has a normal tissue sparing effect. But with this technique, a substantial amount of brain tissue would be irradiated because a margin is required to account for the penumbra and set-up errors. In those external beam radiation therapy series, the issue of late complications has not been addressed specifically, especially for those early series. So the late toxicity profile for external beam radiation therapy for meningioma has not been well-documented. FSRT could potentially decrease the risk of late complications in the brain as a result of decreased treatment volume. In our series, the LC and the late complication rates for benign meningiomas were comparable for the SRS and FSRT groups. The LC for benign meningiomas in the FSRT group appeared to be comparable to the LC reported in those external beam radiotherapy series though our follow-up is still relatively short. 
One point of note is that in our study, most of the patients did not undergo surgery for their primary or recurrent disease before SRS or FSRT (only five out of 53 patients underwent adjunctive subtotal resection) and the LC appeared to be comparable to the data from various surgical, radiation therapy and radiosurgical series. However, because meningiomas usually run an indolent clinical course, a much longer follow-up is required before any conclusions can be drawn.

Regarding the tumor response after treatment, data in the literature showed tumor shrinkage rates ranging from 23 to $56 \% \%^{30,33,40,41}$ after SRS. For FSRT, the Heidelberg group reported a partial tumor regression rate of $14 \%$ but they defined partial tumor regression as a reduction of tumor volume by at least $50 \% .{ }^{44}$ The percentage of tumor with any degree of shrinkage after FSRT was not reported in the study. In our series, it appeared that the tumor shrinkage rate was higher for SRS than FSRT though not significant statistically. At this point, it is difficult to draw a definite conclusion regarding tumor response after SRS compared to FSRT.

In our study, there were three patients with benign meningiomas who developed recurrence 18, 31 and 71 months after treatment respectively. Four out of five patients with atypical or malignant meningiomas who developed local or regional recurrence did so after 21-66 months with three developing recurrence (two local and one regional) after at least three years (37-66 months). This underscores the importance of continued long-term follow-up of these patients with meningiomas.

\section{Complications}

The optic apparatus has lower tolerance to a single high dose of radiation when compared to other cranial nerves and this has been reported in the literature. A dose limit of 8-10 Gy have been recommended in some studies. ${ }^{17-19}$ In our study, one patient without radiologic evidence of local recurrence developed visual deterioration (visual defect present before SRS) after a single dose of 800 cGy was delivered to the optic apparatus. This was before FSRT was available at our institution. This suggested that the dose to the optic apparatus should not exceed $800 \mathrm{cGy}$. A single dose of $800 \mathrm{cGy}$ is usually inadequate to control meningioma so fractionation is recommended for meningiomas abutting the optic apparatus.

The tolerance of the optic apparatus to fractionated radiation was suggested in various conventional radiation therapy studies. ${ }^{45-48}$ One patient in our series who had pre-existing visual deficit received a FSRT dose of $5400 \mathrm{cGy}$ in 30 fractions to $90 \%$ isodose surface so the dose to the optic chiasm was $6000 \mathrm{cGy}$ in 30 fraction, which was in the steep part of the dose-response curve for late effects. Care should be taken not to exceed the dose limit of the optic apparatus during treatment planning. In general, a dose of 54 Gy in 30 fractions is recommended as the dose limit for the optic apparatus. ${ }^{45}$

Radionecrosis and edema of the brain have been concerns after SRS. In an early LINAC-based SRS series from Heidelberg, the reported radionecrosis/edema rate was about $30 \%$ where the mean dose was 29 Gy (range 10-50 Gy). ${ }^{33}$ Recent series utilizing lower SRS doses (20 Gy or less) yielded much lower radionecrosis/edema rates, which were in the range of 3$4 \% .^{30,40}$ In our series, the radionecrosis rate was $2.9 \%(1 / 35)$.
None of the seven reirradiated patients (four SRS and three FSRT) in our series developed any late complications. The range of doses for SRS and FSRT were 1200-4000 cGy and 4500-5000 cGy, respectively. The physical characteristic of stereotactic radiotherapy, namely the sharp dose fall-off beyond the MPD, renders the feasibility of delivering a focal dose of radiation to the tumor volume while minimizing the dose to the surrounding normal brain tissue and critical structures. Stereotactic radiotherapy (SRS or FSRT) appeared to be an attractive treatment option for patients with unresectable recurrent meningiomas who previously received radiation therapy to the brain.

\section{Atypical and malignant meningiomas}

Multiple studies have shown that the recurrence rates for atypical or malignant meningiomas were high even after surgery combined with radiation therapy. ${ }^{49-52}$ However, a tumor control rate of $90 \%$ after total or subtotal resection with or without postoperative radiation therapy supplemented with SRS or FSRT was achieved in one recent stereotactic series. ${ }^{53}$

One problem with atypical and malignant meningiomas is the higher rate of regional recurrence following local treatment with surgery or radiation therapy compared to their benign counterparts. It has been postulated that the spread of tumor cells in the subdural space forming tumor spurs and distant metastases could play a role in the regional recurrence of meningiomas, more frequently for atypical or malignant compared to benign meningiomas. ${ }^{54}$

In our series, five out of the 10 patients (50\%) with atypical/ malignant meningiomas developed local/regional recurrence after treatment and $40 \%$ of the patients who had recurrent disease had regional failure. Our data suggested a much worse TC for atypical or malignant as compared to benign meningiomas. Certainly, more aggressive treatment combining surgery and radiation therapy is necessary to improve and give the best disease control.

\section{CONCLUSION}

SRS appears to be a safe and effective treatment for benign meningiomas for patients who are considered to be poor surgical candidates, those who have recurrent tumors after surgery and/ or radiation therapy, those who have residual tumor after resection and those who decline surgery. For patients with tumors very close to $(\leq 5 \mathrm{~mm})$ or abutting the optic apparatus, fractionated radiation therapy is recommended because of the limitation of the tolerance of the optic apparatus to a single high dose of radiation. FSRT appears to be a reasonable treatment alternative to conventional external beam radiation therapy as it is associated with good tumor control and minimal toxicity in our series. For patients who have previous radiation therapy to the brain, re-irradiation with SRS and FSRT for the treatment of meningiomas seems to be feasible with minimal toxicity. However, the follow-up is still short for the patients treated with SRS or FSRT in our series, so no firm conclusions can be drawn regarding the long-term efficacy or the late toxicity to the central nervous system at this time. For atypical or malignant meningiomas, treatments should include aggressive surgery plus radiation therapy due to high recurrence rates and new treatment options have to be explored to improve outcome. 


\section{ACKNOWLEDGEMENTS}

The authors thank Ms. Shirley Kern (Neuro-oncology nurse) and Ms. Judy Unger (Research nurse) for their invaluable help in the preparation of this manuscript.

\section{REFERENCES}

1. Bondy M, Ligon BL. Epidemiology and etiology of intracranial meningiomas: a review. J Neurooncol 1996; 29(3):197-205.

2. Longstreth WT Jr, Dennis LK, McGuire VM, Drangsholt MT, Koepsell TD. Epidemiology of intracranial meningioma. Cancer 1993; 72(3):639-648.

3. Barbaro NM, Gutin PH, Wilson CB, et al. Radiation therapy in the treatment of partially resected meningiomas. Neurosurgery 1987; 4:525-528.

4. Forbes AR, Goldberg ID. Radiation therapy in the treatment of meningioma: the Joint Center for Radiation Therapy experience 1970 to 1982. J Clin Oncol 1984; 10:1139-1143.

5. Glaholm J, Bloom HJ, Crow JH. The role of radiotherapy in the management of intracranial meningiomas: the Royal Marsden Hospital experience with 186 patients. Int J Radiat Oncol Biol Phys 1990;18(4):61-75.

6. Goldsmith BJ, Wara WM, Wilson CB, Larson DA. Postoperative irradiation for subtotally resected meningiomas. A retrospective analysis of 140 patients treated from 1967 to 1990. J Neurosurg 1994; 80(2):195-201.

7. Solan MJ, Kramer S. The role of radiation therapy in the management of intracranial meningiomas. Int $\mathrm{J}$ Radiat Oncol Biol Phys 1985; 11(4):675-677.

8. Stafford SL, Perry A, Suman VJ, et al. Primarily resected meningiomas: outcome and prognostic factors in 581 Mayo Clinic patients, 1978 through 1988. Mayo Clin Proc 1998; 73(10):936-942.

9. Taylor BW Jr, Marcus RB Jr, Friedman WA, Ballinger WE Jr, Million RR. The meningioma controversy: postoperative radiation therapy. Int J Radiat Oncol Biol Phys 1988; 2:299-304.

10. Kallio M, Sankila R, Hakulinen T, Jaaskelainen J. Factors affecting operative and excess long-term mortality in 935 patients with intracranial meningioma. Neurosurgery 1992; 31(1):2-12.

11. Mirimanoff RO, Dosoretz DE, Linggood RM, Ojemann RG, Martuza RL. Meningioma: analysis of recurrence and progression following neurosurgical resection. J Neurosurg 1985; 62(1):18-24.

12. Awad IA, Kalfas I, Hahn JF, Little JR. Intracranial meningiomas in the aged: surgical outcome in the era of computed tomography. Neurosurgery 1989; 24(4):557-560.

13. Chan RC, Thompson GB. Morbidity, mortality, and quality of life following surgery for intracranial meningiomas. A retrospective study in 257 cases. J Neurosurg 1984;60(1):52-60.

14. Djindjian M, Caron JP, Athayde AA, Fevrier MJ. Intracranial meningiomas in the elderly (over 70 years old). A retrospective study of 30 surgical cases. Acta Neurochir (Wien) 1988; 90(34):121-123.

15. Papo I. Intracranial meningiomas in the elderly in the CT scan era. Acta Neurochir (Wien) 1983; 67(3-4):195-204.

16. Clark BG, Souhami L, Pla C, et al. The integral biologically effective dose to predict brainstem toxicity of hypofractionated stereotactic radiotherapy. Int J Radiat Oncol Biol Phys 1998; 40(3):667-675.

17. Leber KA, Bergloff J, Pendl G. Dose-response tolerance of the visual pathways and cranial nerves of the cavernous sinus to stereotactic radiosurgery. J Neurosurg 1998; 88(1):43-50.

18. Morita A, Coffey RJ, Foote RL, Schiff D, Gorman D. Risk of injury to cranial nerves after gamma knife radiosurgery for skull base meningiomas: experience in 88 patients. J Neurosurg 1999; 90(1):42-49.

19. Tishler RB, Loeffler JS, Lunsford LD, et al. Tolerance of cranial nerves of the cavernous sinus to radiosurgery. Int J Radiat Oncol Biol Phys 1993; 27(2):215-221.

20. Wara WM, Sheline GE, Newman H, Townsend JJ, Boldrey EB. Radiation therapy of meningiomas. Am J Roentgenol Radium
Ther Nucl Med 1975; 123(3):453-458.

21. Sekhar LN, Jannetta PJ. Cerebellopontine angle meningiomas. Microsurgical excision and follow-up results. J Neurosurg 1984; 60(3):500-505.

22. Sekhar LN, Jannetta PJ, Maroon JC. Tentorial meningiomas: surgical management and results. Neurosurgery 1984; 14(3):268275.

23. Sekhar LN, Patel S, Cusimano M, et al. Surgical treatment of meningiomas involving the cavernous sinus: evolving ideas based on a ten year experience. Acta Neurochir Suppl (Wien) 1996; 65:58-62.

24. Sekhar LN, Sen CN, Jho HD, Janecka IP. Meningiomas involving the clivus: a six- year experience with 41 patients. Neurosurgery 1990; 27(5):764-781.

25. Sekhar LN, Sen CN, Jho HD, Janecka IP. Surgical treatment of intracavernous neoplasms: a four-year experience. Neurosurgery 1989; 24(1):18-30.

26. Condra KS, Buatti JM, Mendenhall WM, et al. Benign meningiomas: primary treatment selection affects survival. Int $\mathrm{J}$ Radiat Oncol Biol Phys 1997; 39(2): 427-436.

27. Maguire PD, Clough R, Friedman AH, Halperin EC. Fractionated external-beam radiation therapy for meningiomas of the cavernous sinus. Int J Radiat Oncol Biol Phys 1999; 44(1):75-79.

28. Maire JP, Caudry M, Guerin J, et al. Fractionated radiation therapy in the treatment of intracranial meningiomas: local control, functional efficacy, and tolerance in 91 patients. Int $\mathbf{J}$ Radiat Oncol Biol Phys 1995; 33(2):315-321.

29. Miralbell R, Linggood RM, de la Monte S, et al. The role of radiotherapy in the treatment of subtotally resected benign meningiomas. J Neurooncol 1992; 2:157-164.

30. Chang SD, Adler JR Jr. Treatment of cranial base meningiomas with linear accelerator radiosurgery. Neurosurgery 1997; 41(5):10191025.

31. Chang SD, Adler JR Jr, Martin DP. LINAC radiosurgery for cavernous sinus meningiomas. Stereotact Funct Neurosurg 1998; 71(1):43-50.

32. Duma CM, Lunsford LD, Kondziolka D, Harsh GR 4th, Flickinger JC. Stereotactic radiosurgery of cavernous sinus meningiomas as an addition or alternative to microsurgery. Neurosurgery 1993; 32(5):699-704.

33. Engenhart R, Kimmig BN, Hover KH, et al. Stereotactic single high dose radiation therapy of benign intracranial meningiomas. Int $\mathbf{J}$ Radiat Oncol Biol Phys 1990; (4):1021-1026.

34. Hakim R, Alexander E III, Loeffler JS, et al. Results of linear accelerator-based radiosurgery for intracranial meningiomas. Neurosurgery 1998; 42(3):436-454.

35. Kondziolka D, Flickinger JC, Perez B. Judicious resection and/or radiosurgery for parasagittal meningiomas: outcomes from multicenter review. Gamma Knife Meningioma Study Group. Neurosurgery 1998, 43(3):405-413.

36. Kondziolka D, Lunsford LD, Coffey RJ, Flickinger JC. Stereotactic radiosurgery of meningiomas. J Neurosurg 1991; 74(4):552-559.

37. Kurita H, Sasaki T, Kawamoto S, et al. Role of radiosurgery in the management of cavernous sinus meningiomas. Acta Neurol Scand 1997; 96(5):297-304.

38. Nicolato A, Ferraresi P, Foroni R, et al. Gamma Knife radiosurgery in skull base meningiomas. Preliminary experience with 50 cases. Stereotact Funct Neurosurg 1996; 66 Suppl 1:112-120.

39. Pendl G, Schrottner O, Eustacchio S, Ganz JC, Feichtinger K. Cavernous sinus meningiomas--what is the strategy: upfront or adjuvant gamma knife surgery? Stereotact Funct Neurosurg 1998; 70(Suppl 1):33-40.

40. Shafron DH, Friedman WA, Buatti JM, Bova FJ, Mendenhall WM Linac radiosurgery for benign meningiomas. Int J Radiat Oncol Biol Phys 1999; 43(2): 321-327.

41. Subach BR, Lunsford LD, Kondziolka D, Maitz AH, Flickinger JC. Management of petroclival meningiomas by stereotactic radiosurgery. Neurosurgery $1998 ; 42(3): 437-443$.

42. Tanaka T, Kobayashi T, Kida Y. Growth control of cranial base meningiomas by stereotactic radiosurgery with a gamma knife unit. Neurol Med Chir (Tokyo) 1996; 36(1): 7-10.

43. Valentino V, Schinaia G, Raimondi AJ. The results of radiosurgical 
management of 72 middle fossa meningiomas. Acta Neurochir (Wien) 1993; 122(1-2):60-70.

44. Debus J, Wuendrich M, Pirzkall A, et al. High efficacy of fractionated stereotactic radiotherapy of large skull base meningiomas: long term results. J Clin Oncol 2001;19(15): 3547-3553.

45. Goldsmith BJ, Rosenthal SA, Wara WM, Larson DA. Optic neuropathy after irradiation of meningioma. Radiology 1992; 185(1):71-76.

46. Jiang GL, Tucker SL, Guttenberger R, et al. Radiation-induced injury to the visual pathway. Radiother Oncol 1994; 30(1):17-25.

47. Parsons JT, Bova FJ, Fitzgerald CR, Mendenhall WM, Million RR. Radiation optic neuropathy after megavoltage external-beam irradiation: analysis of time-dose factors. Int J Radiat Oncol Biol Phys 1994; 30(4):755-763.

48. Young WC, Thornton AF, Gebarski SS, Cornblath WT. Radiationinduced optic neuropathy: correlation of MR imaging and radiation dosimetry. Radiology 1992; 185(3):904-907.

49. Coke CC, Corn BW, Werner-Wasik M, Xie Y, Curran WJ Jr.
Atypical and malignant meningiomas: an outcome report of seventeen cases. J Neurooncol 1998; 39(1): 65-70.

50. Dziuk TW, Woo S, Butler EB, et al. Malignant meningioma: an indication for initial aggressive surgery and adjuvant radiotherapy. J Neurooncol 1998; 37(2):177-188.

51. Milosevic MF, Frost PJ, Laperriere NJ, Wong CS, Simpson WJ. Radiotherapy for atypical or malignant intracranial meningioma. Int J Radiat Oncol Biol Phys 1996; 34(4):817-822.

52. Palma L, Celli P, Franco C, Cervoni L, Cantore G. Long-term prognosis for atypical and malignant meningiomas: a study of 71 surgical cases. J Neurosurg 1997; 86(5):793-800

53. Zakhary R, Brat DJ, Wharam M, Williams J. Stereotactic radiosurgery for atypical and malignant meningiomas. J Radiosurg 1998; 1:251-256.

54. de Vries J, Wakhloo AK. Repeated multifocal recurrence of grade I, grade II, and grade III meningiomas: regional multicentricity (primary new growth) or metastases? Surg Neurol 1994; 41(4):299-305. 